\title{
Nurses' knowledge and attitudes toward pain assessment and management for adult sickle cell disease patients during sickling crisis
}

\author{
Shafeeqa Hasan Yaqoob ${ }^{* 1}$, Husain Ali Nasaif ${ }^{2}$ \\ ${ }^{1}$ Ministry of Health, Kingdom of Bahrain \\ ${ }^{2}$ Royal College of Surgeon in Ireland, Medical University of Bahrain, Kingdom of Bahrain
}

Received: July 5, 2015

DOI: $10.5430 /$ cns.v3n4p36

\author{
Accepted: July 24, 2015 \\ Online Published: August 10, 2015
}

URL: http://dx.doi.org/10.5430/cns.v3n4p36

\begin{abstract}
In the kingdom of Bahrain an estimated 18,000 people suffer from Sickle Cell Disease (SCD) and many experience periodic episodes of sickling crisis. Research studies that examine the knowledge and attitudes of nurses toward pain assessment and management of SCD patients are limited especially in the Middle East. This study aims to assess the level of knowledge and attitudes of nursing staff regarding pain assessment and management of patients with SCD during sickling crisis. A quantitative study design was utilized to recruit a convincence sample of 30 staff nurses working in adult SCD wards in one of governmental hospital in the Kingdom of Bahrain. A modified version of Nurses' Knowledge and Attitude Survey questionnaire regarding Pain was used to examine the research variables. The results of the study showed that a mean score of knowledge was 15.8 out of $33(47.8 \%$ out of $100 \%)$. This finding indicates that staff nurses had poor knowledge and negative attitudes toward SCD pain assessment and management. The findings showed no significant difference in the mean score of knowledge in relation with nationality $(p=.693)$, age $(p=.966)$, level of education $(p=.732)$, years of experience $(p=.887)$, and previous training courses or workshops on pain management $(p=.877)$. This study suggests the need for implementing of specific strategies to effectively educate the staff nurses about pain assessment and management, and integrate pain management as a major component of the hospital in-house training programs.
\end{abstract}

Key Words: Sickle cell disease, Pain management, Knowledge, Attitude

\section{INTRODUCTION}

According to the report by the World Health Organization, ${ }^{[1]}$ nearly $5 \%$ of the world's population carries genes responsible for haemoglobinopathies. Yearly, about 300,000 infants are born with major haemoglobin disorders such as Sickle Cell Disease (SCD), Glucose-6-Phosphate Dehydrogenase (G6PD) and thalassemia. SCD is a hereditary chronic genetic blood and a widespread autosomal recessive disorder, characterized by abnormal sickle-shape of red blood cells. These cells block the small blood vessels and interrupt the supply of oxygen to body tissues, causing inflammation, tissue damage, physical dysfunction and intense episodes of severe pain. ${ }^{[2,3]}$ The highest incidence of the disease is found in Africa. ${ }^{[4]}$ It is also widely spread in North America, and Eastern Mediterranean Region. ${ }^{[5]}$ It is the most common hereditary blood disorder in the Kingdom of Bahrain. In a retrospective study from 1982 to 1987 the prevalence of SCD among the neonatal Bahrainis was $2.1 \%$. ${ }^{[6]}$ The rate came down to $0.4 \%$ in $2010 .{ }^{[7]}$ Despite the decline in the birth prevalence rate, the mortality and morbidity rate of the dis-

*Correspondence: Shafeeqa Hasan Yaqoob; Email: tahayo76@hotmail.com; Address: Ministry of Health, Kingdom of Bahrain. 
ease still remain high. An estimated 18,000 SCD patients in the Kingdom of Bahrain, ${ }^{[8]}$ but only 5,000 patients are registered in the Ministry of Health and being are treated for SCD and related complications at the largest governmental hospital. ${ }^{[9]}$ Complications such as chronic anemia, and acute chest syndrome, splenic and renal dysfunction have significantly increased the morbidity and mortality rate. ${ }^{[10]}$ As a result twenty patients died in 2009, increasing to 46 in 2014. ${ }^{[9,11]}$ Severe acute pain is the most common symptom reported by SCD patients and it is the main cause for hospitalization. Approximately 100 patients per day visit the Accident and Emergency of the largest government hospital in the country. Between 300 to 400 patients visit the primary health care centers daily to seek treatment for acute VOC. ${ }^{[9,11]}$ It has been noticed also that the admission and hospital length of stay to manage VOC and other SCD related complications have increased. In 2012, 4,123 patients were admitted with the average of 7 days of hospital length of stay compared with 3,940 patients and 5.7 days in 2009. Seven days of hospital length of stay is relatively high when taking into consideration the interruption of patient's social role, the risk of infection, and treatment costs. Government expenditure exceeded 22 million US dollars for 2012. ${ }^{[12]}$ The increased length of hospital stay and mortality rate post the question whether pain assessment and management strategies are successfully applied in the health care facilities. Nurses play a vital role in assessing, managing, and evaluating SCD pain crisis. Overall pain assessment and management remain a challenging issue for both nursing staff and SCD patients.

Several research studies have examined nurses' knowledge and attitudes about pain assessment and management, however, most of these studies focused on nurses who take care of cancer, post-operative and Emergency patients. ${ }^{[13-17]}$ The findings from these studies revealed that nurses had inadequate knowledge about pain assessment and management. ${ }^{[13,18-20]}$ Previous research studies have identified several barriers to adequate pain management in SCD such as: sociocultural factors, the concerns regarding addiction, disbelief of the health care professional and the lack of knowledge. ${ }^{[21-24]}$

Research studies that examine the knowledge and attitudes of nurses toward pain assessment and management of SCD patients are limited especially in the Middle East. Therefore, this study was conducted to assess the level of knowledge and attitudes of nursing staff regarding pain assessment and management of adult SCD patients. The study aimed to answer the following questions: (1) What is the nursing staffs' level of knowledge related to pain assessment and management for adult SCD patients? (2) Is there any statistical significance difference in the mean score of knowledge in relation

Published by Sciedu Press to demographic and personal characteristics?

\section{METHODS}

This study was conducted over an 8 months period between September 2010 and May 2011 in two adult SCD wards in one of governmental hospital in the Kingdom of Bahrain. These wards were designed to provide adult care services for SCD in-patients with a capacity of 22 beds and 18 staff nurses in each ward. SCD patients who need hospital admission might be admitted to other medical wards because of bed shortage in these two wards. A quantitative, descriptive, cross-sectional design was used to guide the research process. A sample of 30 nursing staff was recruited using a non-probability convenience sampling method. The inclusion criteria for the study sample were as follows: (1) Nurses who have at least one year of working experience as a staff nurse and, (2) at least 3 months of working experience in SCD wards. Subjects who did not meet the inclusion criteria were excluded from the study.

The Nurses Knowledge and Attitude questionnaire Regarding Pain (KASRP) was used to measure the nurses' level of knowledge and their attitude toward SCD pain assessment and management. KASRP is a self-administered questionnaire, was developed by Betty Ferrel and Margo McCaffery in 1987 and widely used by many scholars. ${ }^{[13,18,20,25,26]}$ The instrument was designed to examine nurses' knowledge about pain assessment and management in general giving more attention to pharmacological interventions. The Cronbach Alpha coefficient was 0.70 for internal consistency and 0.80 for test-retest reliability. A permission was obtained from the developer to modify the instrument in order to suit the purpose of the study. Field experts including consultant in hematology and expert in research were consulted to ensure the instrument's face and content validity. Five questions were modified based on recommendations made by field experts before the pilot study. Aspirin in Q5 was replaced with Naproxin and gabapentin (Neurontin) in Q20 was replaced with lyrica (pregabalin). Moreover, Benzodiazepines in Q21 was replaced with Valium, Codeine in Q25 was changed to Sosegon, and Hydromorphone (Dilaudid) in Q30 was replaced with MST and Gabapentin with Lyrica (pregabalin). The modified KASRP instrument consists of 33 questions without the demographic variables and personal characteristics; 18 True and False questions, 11 Multiple-Choice Questions (MCQs), and 2 case studies with 2 questions for each. The demographic and personal section focuses on age, nationality, level of education, years of working experience and previous training on pain assessment. The developers of KASRP suggested not to categorize questions as either knowledge or attitudes, because most of 
the questions measure both variables at the same time. ${ }^{[27]}$

A pilot study was conducted with 5 nurses who had similar characteristics of the study sample to ensure the clarity of questions. Nurses participated in the pilot study were not included in the study sample. No changes have been made on the questionnaire after the conduct of the pilot study. Prior to the data collection, the ethical approval was obtained from the ethics committee of Royal College of Surgeon in IrelandMedical University of Bahrain and Research Committee in the hospital where the study took a place. The purpose of the study was explained to the participants and consent was obtained prior to the data collection. Confidentiality was assured and personal data that might identify the study participants' were not gathered. The participants were instructed to complete and return the questionnaire in sealed envelope.

\section{Data analysis}

Data from the KASRP were analyzed using SPSS version 18.0 software. Descriptive statistics, including frequency, per- centage, mean and standard deviation were used to describe the demographic data. The percentage of correct and incorrect answers for each item was calculated. Mann-Whitney and Kruskal-Wallis tests were used to detect differences in mean total score of knowledge in relation to demographic and personal characteristics.

\section{RESULTS}

\subsection{Demographic \& personal characteristics}

Thirty nurses completed and returned the survey with overall response rate of $88 \%$. The majority were non-Bahrainis $(n=19,63.3 \%)$, and were between $31-40$ years old $(56.7 \%)$. Twenty-four nurses $(80 \%)$ had associated diploma in nursing, and $20 \%$ held bachelor degrees. Years of working experience ranged from 5 years or less $(10 \%)$ to more than 6 years (90\%). Only $13.3 \%(n=4)$ attended a training program on pain management and that was during their BSc nursing studies. The demographic and personal characteristics of the study sample are set out in Table 1.

Table 1. Demographic characteristics

\begin{tabular}{|c|c|c|}
\hline Characteristic & $\mathbf{N}$ & $\%$ \\
\hline \multicolumn{3}{|l|}{ Nationality } \\
\hline Bahraini & 11 & 36.7 \\
\hline Non-Bahraini & 19 & 63.3 \\
\hline Total & 30 & 100.0 \\
\hline \multicolumn{3}{|l|}{ Age Range } \\
\hline $21-30$ & 5 & 16.7 \\
\hline $31-40$ & 17 & 56.7 \\
\hline$>40$ & 8 & 26.7 \\
\hline Total & 30 & 100.0 \\
\hline \multicolumn{3}{|c|}{ Highest Education } \\
\hline Diploma & 24 & 80.0 \\
\hline Bachelor & 6 & 20.0 \\
\hline Total & 30 & 100.0 \\
\hline \multicolumn{3}{|c|}{ Years of Working Experience (year) } \\
\hline $1-5$ & 3 & 10.0 \\
\hline $6-10$ & 9 & 30.0 \\
\hline $11-15$ & 10 & 33.3 \\
\hline$>15$ & 8 & 26.7 \\
\hline Total & 30 & 100.0 \\
\hline \multicolumn{3}{|c|}{ Have you attended any pain management course, training, workshop or conference? } \\
\hline Yes & 4 & 13.3 \\
\hline No & 26 & 86.7 \\
\hline Total & 30 & 100.0 \\
\hline
\end{tabular}




\subsection{Knowledge and attitudes regarding pain manage- ment}

The questionnaire examined three areas: pain assessment, nurses' perceptions about pain management and pharmacological interventions. Tables 2 and 3 summarize the data concerning the level of knowledge about pain assessment and management which was tested through True and False questions and MCQs. The score ranged from 0 to 33 and the total was calculated using the number of correct answers which were then converted to percentage. Questions that were left unanswered were considered incorrect. The participants scored above $80 \%$ in 6 questions and most of these questions were examining knowledge about pharmacological interventions. They scored between $50 \%$ and $70 \%$ in nine questions and below $50 \%$ in 18 questions. The overall mean score of the level of knowledge was 15.8 out of $33(47 \%$ out of $100 \%)$. The highest score for all questions was $66.6 \%$ and lowest score was $18.1 \%$. The findings revealed that nurses had very poor knowledge about many aspects of SCD pain assessment and management. For example with regard to True and False questions, only $3(10 \%)$ correctly identified that vital signs are not always reliable indicators of the intensity of a patient's pain and 4 (13.3\%) correctly identified that patient may sleep in spite of severe pain. Two thirds $(n=23,76.7 \%)$ considered Promethazine (Phenergan) as a reliable potentiators of opioid analgesics. They also demonstrated poor knowledge about Morphine dosage administration (Q21, Q28), intensity of pain (Q25) and manifestations of physical dependence following discontinuation of opioid (Q29). On the other hand, the participants demonstrated very good knowledge about combination of analgesics (Q6), opioid analgesics (Q13), Valium (Q17) and characteristics of Narcotic and opioid addiction (Q18), administration route of opioid analgesics (Q19), peak effect of Morphine (Q27). The difference in the mean score was measured by Mann-Whitney and Kruskal-Wallis tests. The findings showed no significant difference in the mean score of knowledge in relation with nationality $(p=.693)$, age $(p=$ $.966)$, level of education $(p=.732)$, years of experience $(p$ $=.887)$, and previous training courses or workshops on pain management $(p=.877)$. However, it is difficult to detect the significance when the sample size is small and the number of participants in each group is not equal.

Table 2. Staff nurses' responses to True and False questions (correct answers are in bold and italic)

\begin{tabular}{|c|c|c|c|c|}
\hline \multirow{2}{*}{ True and False Questions } & \multicolumn{2}{|l|}{$\mathbf{F}$} & \multicolumn{2}{|l|}{$\mathbf{T}$} \\
\hline & $\mathbf{N}$ & $\%$ & $\mathbf{N}$ & $\%$ \\
\hline Q1 Vital signs are always reliable indicators of the intensity of a patient's pain. (F) & 27 & 90.0 & 3 & 10.0 \\
\hline Q2 Patients who can be distracted from pain usually do not have severe pain. (F) & 19 & 63.3 & 11 & 36.7 \\
\hline Q3 Patients may sleep in spite of severe pain. (T) & 26 & 86.7 & 4 & 13.3 \\
\hline $\begin{array}{l}\text { Q4 Naproxin and other nonsteroidal anti-inflammatory agents are NOT effective analgesics for painful Sickle } \\
\text { Cell Disease (SCD) Crisis. (F) }\end{array}$ & 13 & 43.3 & 17 & 56.7 \\
\hline $\begin{array}{l}\text { Q5 Respiratory depression rarely occurs in patients who have been receiving stable doses of opioids over a } \\
\text { period of months. (T) }\end{array}$ & 10 & 33.3 & 20 & 66.7 \\
\hline $\begin{array}{l}\text { Q6 Combining analgesics that work by different mechanisms (e.g., combining an opioid with an NSAID) may } \\
\text { result in better pain control with fewer side effects than using a single analgesic agent. (T) }\end{array}$ & 5 & 16.7 & 25 & 83.3 \\
\hline $\begin{array}{l}\text { Q7 Research shows that promethazine (Phenergan) is reliable a potentiators (to increase effect) of opioid } \\
\text { analgesics. (F) }\end{array}$ & 23 & 76.7 & 7 & 23.3 \\
\hline Q8 Opioids should not be used in patients with a history of substance abuse. (F) & 18 & 60.0 & 12 & 40.0 \\
\hline Q9 Morphine has a dose ceiling (i.e., a dose above which no greater pain relief can be obtained). (F) & 17 & 56.7 & 13 & 43.3 \\
\hline Q10 Elderly patients cannot tolerate opioids for pain relief. (F) & 11 & 36.7 & 19 & 63.3 \\
\hline Q11 Patients should be encouraged to tolerate as much pain as possible before using an opioid. (F) & 26 & 86.7 & 4 & 13.3 \\
\hline Q12 Patients’ spiritual beliefs may lead them to think pain and suffering are necessary. (T) & 14 & 46.7 & 16 & 53.3 \\
\hline $\begin{array}{l}\text { Q13 After an initial dose of opioid analgesic is given, subsequent doses should be adjusted in accordance with } \\
\text { the individual patient's response. (T) }\end{array}$ & 3 & 10.0 & 27 & 90.0 \\
\hline Q14 Giving patients sterile water by injection (placebo) is a useful test to determine if the pain is real. (F) & 20 & 66.7 & 10 & 33.3 \\
\hline $\begin{array}{l}\text { Q15 If the source of the patient's pain is unknown, opioids should not be used during the pain evaluation } \\
\text { period, as this could mask the ability to correctly diagnose the cause of pain. (F) }\end{array}$ & 25 & 83.3 & 5 & 16.7 \\
\hline Q16 Anticonvulsant drugs such as lyrica (pregabalin) produce optimal pain relief after a single dose. (F) & 10 & 33.3 & 20 & 66.7 \\
\hline Q17 Valium is not effective pain relievers unless the pain is due to muscle spasm. (T) & 4 & 13.3 & 26 & 86.7 \\
\hline $\begin{array}{l}\text { Q18 Narcotic/opioid addiction is defined as a chronic neurobiologic disease, characterized by behaviors that } \\
\text { include one or more of the following: impaired control over drug use, compulsive use, continued use despite } \\
\text { harm, and craving. (T) }\end{array}$ & 5 & 16.7 & 25 & 83.3 \\
\hline
\end{tabular}


Table 3. Staff nurses' responses to Multiple choice questions (correct answers are in bold and italic)

\begin{tabular}{|c|c|c|c|c|}
\hline \multirow{2}{*}{ Multiple Choice Questions } & \multicolumn{2}{|l|}{$\mathbf{F}$} & \multicolumn{2}{|l|}{$\mathbf{T}$} \\
\hline & $\mathbf{N}$ & $\%$ & $\mathbf{N}$ & $\%$ \\
\hline $\begin{array}{l}\text { Q19 The recommended route for administration of opioid analgesics for patients with sudden onset } \\
\text { severe SCD crisis pain: Intravenous }\end{array}$ & 1 & 3.3 & 29 & 96.7 \\
\hline $\begin{array}{l}\text { Q20 Which of the following analgesic medications is considered the drug of choice for the } \\
\text { treatment of prolonged moderate to severe pain for SCD patients? Morphine }\end{array}$ & 10 & 33.3 & 20 & 66.7 \\
\hline $\begin{array}{l}\text { Q21 Which of the following IV doses of morphine administered over a } 4 \text { hour period would be } \\
\text { equivalent to } 30 \mathrm{mg} \text { of oral morphine given q } 4 \text { hours? Morphine } 10 \mathbf{~ m g ~ I V ~}\end{array}$ & 22 & 73.3 & 8 & 26.7 \\
\hline Q22 Analgesics for sever SCD pain should initially be given: Around the clock on a fixed schedule & 12 & 40.0 & 18 & 60.0 \\
\hline $\begin{array}{l}\text { Q23 The most likely reason a patient with pain would request increased doses of pain medication is: } \\
\text { The patient is experiencing increased pain. }\end{array}$ & 12 & 40.0 & 18 & 60.0 \\
\hline Q24 Which of the following is useful for treatment of SCD pain? All of the above & 15 & 50.0 & 15 & 50.0 \\
\hline Q25 The most accurate judge of the intensity of the patient's pain is: The patient & 22 & 73.3 & 8 & 26.7 \\
\hline $\begin{array}{l}\text { Q26 Which of the following describes the best approach for cultural considerations in caring for } \\
\text { patients in pain: Patients should be individually assessed to determine cultural influences. }\end{array}$ & 5 & 16.7 & 25 & 83.3 \\
\hline Q27 The time to peak effect for morphine given IV is: $\mathbf{1 5}$ min. & 7 & 23.3 & 23 & 76.7 \\
\hline Q28 The time to peak effect for morphine given orally is: 1-2 hours & 18 & 60.0 & 12 & 40.0 \\
\hline $\begin{array}{l}\text { Q29 Following abrupt discontinuation of an opioid, physical dependence is manifested by the } \\
\text { following: Sweating, yawning, diarrhea and agitation with patients when the opioid is abruptly } \\
\text { discontinued }\end{array}$ & 25 & 83.3 & 5 & 16.7 \\
\hline
\end{tabular}

\section{DISCUSSION}

This is the first study conducted in Bahrain to examine the level of knowledge and attitudes of nursing staff toward pain assessment and management of adult patients with SCD. Al Maran examined surgical nurses' knowledge about post-operative pain management in 2007 at one hospital in Bahrain. In general, the results indicate that staff nurses in SCD wards have a poor knowledge of pain assessment and management. In this study, the mean score of knowledge was $47.8 \%$. This finding was consistent and similar to those obtained by Lui et al. and Tsai et al. The mean score obtained by Lui et al. was $47.72 \%$, while Tsai et al. had an overall score of $49.2 \% .{ }^{[20,28]}$ Furthermore, the mean score of this study was higher than the score reported by Al Maran $(37.8 \%),{ }^{[29]}$ and Yava and his colleagues $(39.65 \%) .{ }^{[18]}$ However, few studies that used same instrument reported higher score than our study. ${ }^{[13,17,26,30,31]}$

Poor knowledge in this study could be attributed to several reasons. One possible reason is that the majority of nurses $(63.3 \%)$ working in adult SCD wards were expatriates from India. Taking into the consideration that SCD is not a common disease in this country, this might be a contributing factor for poor level of knowledge about pain assessment and management of adult patients with SCD. However, this argument is not solid enough due to the fact that the majority of the study participants had worked in SCD wards for more than five years. In addition, the findings from the study did not reveal a significant difference in the mean score in relation to nationality of nursing staff. Findings from literature revealed that, the level of education influences the level of knowledge. However, in this study the level of education was not found to be a factor that influenced the level of knowledge as the findings did not reveal differences between nurses holding Associated Diploma and Bachelor Science in Nursing $(p=.732)$. This finding could possibly be explained as only $20 \%$ of study sample held a Bachelor's degree. With regards to training courses, only 4 nurses (13.3\%) attended workshops and few educational sessions about pain assessment and management. These educational sessions were about pain assessment in general during their BSc nursing studies. Lack of training and continuing education program could contribute to poor knowledge about pain assessment and management. It has been well documented in the literature that educational programs improve nurses' knowledge and skills for pain management. Abdalrahim et al. reported an increase in the mean score of knowledge from $45.7 \%$ to $75 \%$ among nurses following pain management program. ${ }^{[32]}$ Likewise, Qadire had found significant improvement of nurses' knowledge and attitude following six hours of educational course on pain assessment and management. ${ }^{[33]}$

Self-report of pain is the most reliable indicator of pain ${ }^{[34]}$ yet in this study only 8 participants $(26.7 \%)$ believed that the patient was the most accurate judge of the intensity of the pain. This can be supported further by their response to the case study questions (30 A and $31 \mathrm{~A}$ ). In both case studies, the participants did not believe the self-report of pain for smiling as well as grimacing patients who gave the same pain score. Interestingly, $90 \%$ of the participants agreed that 
vital signs are an indicators for the intensity of patients' pain. For that reason, $73.3 \%$ of participants reduced the dose of the analgesia for smiling patients and $63.3 \%$ did the same for grimacing patients. This finding is similar to Kaki et al. ${ }^{[35]}$ Lui et al. and Tse and Chan which support the idea that nurses still rely on vital signs and patients behaviour as indicator of the intensity of a patients' pain. ${ }^{[20,36]}$

In addition, this study found that $66.7 \%$ of participants agreed that placebo injection is useful tool to determine whether patient on pain or not. Conversely, $86.1 \%$ of the nurses in McCaffery and Robinson study disagreed with using of placebos to assess patient pain. ${ }^{[34]}$ Placebos may be effective in management of pain in some conditions, but involving deception in administering raises ethical issues, therefore some institutions have banned its use.

Regarding pain management perceptions, the majority of participants were not supportive to the concept that patients can be distracted from pain (Q2) and can sleep in spite of severe pain $(\mathrm{Q} 3)$. The mean score for incorrect answers to both questions was $63.3 \%$ (19 out of 30) and 86.7\% (26 out of 30) respectively. These results were consistent with some of previous research studies; ${ }^{[20,30]}$ and inconsistent with others, ${ }^{[34,37]}$ indicating nurses' misconception about pain and its management. The participants may view pain as suffering and discomfort experience therefore they expect patients to show behavior acts of pain such as grimacing and crying.

The majority of participants $(90 \%)$ correctly identified that subsequent doses of opioid medication should be adjusted according to individual responses, however clinically this wasn't obvious in the case studies, which may indicate a lack of practice and a gap between the knowledge and practice. Although, the majority of participants rated both patients pain incorrectly, it was also noted with concern that $73.3 \%$ would have given Ali less than the maximum dose of morphine ordered by the physicians. Moreover, $63.3 \%$ would have done the same for Hasan. Inconsistencies were found in this study sample, which was similar to previous reports. ${ }^{[28,30,38]}$ Lack of knowledge in the pharmacology of morphine may have contributed to this action therefore further research is needed to highlight the reasons behind such inconsistencies.

\subsection{Implications}

This study provides information for hospital and nursing administrators that may guide and ensure the implementation of effective strategies to improve nurses' clinical assessment skills and pain management for SCD patients. A shortage of nurses and increased workload are strongly linked with ineffective assessment which directly affect pain management. It is important to address the shortage and workload

Published by Sciedu Press issue when developing a strategy to improve nurses' clinical assessment skills and manage SCD patients' painful crisis. Findings from this study could pave the way for further research studies on barriers to effective pain assessment and management other than lack of knowledge. Continuing education for nurses on management of patients with sickle cell disease is necessary to ensure better quality in health care. Furthermore, the findings from this study inform the academics and educators about the importance of integrating SCD pain assessment and management within the curriculum of undergraduate nursing programs. Finally, for better quality of care, there is a need for clinical pathway and standard of care for the management of the acute painful crisis and a specialize pain management nurses to educate, promote and provide optimal nursing care. Recently, the Ministry of Health in the Kingdom of Bahrain launched a Hereditary Blood Disorder Center with capacity of 90 beds to provide care for SCD patients. A new protocol was introduced; however, there is still lack of constant pattern of practice.

\subsection{Limitations of the study}

The sample size of this study was small. The study only examined the level of knowledge among nurses working in SCD wards. Considering the fact that many SCD patients receive inpatient care in the Accident \& Emergency and some are admitted in medical and surgical wards due to shortage of bed; therefore, the findings from this study cannot be generalized onto nurses working in these wards. Therefore, there is a need for multi-center comparative study recruiting a larger sample from Accident and Emergency and other medical and surgical wards. KASRP examines the knowledge about pharmacological interventions only. Further studies, assessing the knowledge and attitudes of nurses toward non pharmacological interventions including distraction, cognitive behavioral therapy and coping strategies is highly recommended.

\section{Conclusion}

The finding of this study revealed that the staff nurses in adult SCD wards had poor knowledge about SCD pain assessment and management. Lack of knowledge among health care providers including nurses is one of the barriers to effective pain assessment and management. The level of knowledge reflects the quality of care that nurses are providing to patients under their responsibilities. There is an urgent need to improve nurses' pain assessment skills for SCD patients through regular and continues in house educational and professional development program. The effect of educational program on nurses' knowledge and attitudes after implementation need to be evaluated by future research studies.

\section{ACKNOWLEDGEMENTS}

This study was done and submitted in part fulfillment of the 
degree of Master in Sciences in Nursing, Faculty of Nursing \& Midwifery, Royal College of Surgeon in Ireland, Medical University of Bahrain, 2013. We would like to extend our appreciation to Palm Association for sponsoring the primary investigator of this study to continuing the master education.

\section{CONFLicts OF InTEREST Disclosure}

The authors declare no competeing interest.

\section{REFERENCES}

[1] Management of haemoglobin disorders: Report of joint WHO-TIF meeting [Internet]. Nicosia, Cyprus: World Health Organization; 2007 November 16-18 [cited 2015 June 2]. Available from: http: //www . who.int/genomics/WHO-TIF_genetics_final.pdf

[2] Hematopathology: Leukemia, Lymphoma, Anemia, Acute myeloid leukemia, Sickle-cell disease, Multiple myeloma, B-cell chronic lymphocytic leukemia. Memphis, USA: Books LLC; 2011.50 p.

[3] The pathophysiology of sickle cell disease: Cellular, molecular and biochemical mechanisms. Saarbruucken VDM Verlag Dr. Muuller; 2009.

[4] Sickle-cell disease and other haemoglobin disorders [Internet]. World Health Organization; 2011 [cited 2015 March 31]. Available from: ht tp://www. who. int/mediacentre/factsheets/fs308/en/

[5] Dunlop R, Bennett K. Pain management for sickle cell disease in children and adults. Cochrane Database of Systematic Reviews. 2006 2. http://dx.doi.org/10.1002/14651858

[6] Nadkarni K, Al Arrayed S, Bapat J. Incidence of genetic disorders of haemoglobins in the hospital population of Bahrain. Bahrain Medical Bulletin. 1991; 13: 19-23.

[7] Al Arrayed S, Al Hajeri A. Newborn Screening Services in Bahrain between 1985 and 2010. Advances in Hematology. 2012. http: //dx.doi.org/10.1155/2012/903219

[8] Singh M. Bahrain winning war on sickle cell disease. Gulf Daily News. 2010 July 11.

[9] Unnikrishnan R. Special sickle cell day care unit soon. Gulf Daily News. 2015 June 11

[10] Stuart MJ, Nagel RL. Sickle-cell disease. The Lancet. 2004; 364: 9-15.

[11] Medical Review Office. Principle diagnosis report (ICD10): Sickle cell disease Unpublished statistics; Salmaniya Medical Complex, Kingdom of Bahrain. 2014.

[12] Bahrain Health statistics. Ministry of Health, Kingdom of Bahrain 2012.

[13] Moceri JT, Drevdahl DJ. Nurses' Knowledge and Attitudes Toward Pain in the Emergency Department. Journal of Emergency Nursing. 2014 January; 40(1): 6-12.

[14] Abed El-Rahman M, Al Kalaldeh MT, Muhbes F. Knowledge and attitude towards pain management: A comparison between oncology and non-oncology nurses in Jordan. International Journal of Advanced Nursing Studies. 2013; 2(2): 95-100. http://dx.doi.o $\mathrm{rg} / 10.14419 / \mathrm{ijans} . \mathrm{v} 2 \mathrm{i} 2.1006$

[15] Elumelu TN, Adenipeku AA, Eriba LO, et al. Knowledge of cancer pain management among nurses in a Nigerian tertiary health institution. Journal of Nursing Education and Practice. 2013; 4(4): 74-80.

[16] Yildirim YK, Cicek F, Uyar M. Knowledge and attitudes of Turkish oncology nurses about cancer pain management. Pain Management Nursing: Official Journal of the American Society of Pain Management Nurses. 2008; 9: 17-25. PMID:18313586. http: //dx.doi.org/10.1016/j.pmn.2007.09.002
[17] Xue Y, Schulman-Green D, Czaplinski C, et al. Pain Attitudes and Knowledge among RNs, Pharmacists, and Physicians on an Inpatient Oncology Service. Clinical Journal of Oncology Nursing. 2007; 11(5): 687-695. PMID:17962176. http://dx.doi .org/10.1188 107. CJON.687-695

[18] Yava A, Cicek H, Tosun N, et al. Knowledge and attitudes of nurses about pain management in Turkey. International Journal of Caring Sciences. 2013 September; 6(3): 494-505.

[19] Al-Shaer D, Hill PD, Anderson MA. Nurses' Knowledge and Attitudes Regarding Pain Assessment and Intervention. Medsurg Nursing: Official Journal of the Academy of Medical-Surgical Nurses. 2011; 20(1): 7-11.

[20] Lui L, So W, Fong D. Knowledge and attitudes regarding pain management among nurses in Hong Kong medical units. Journal of Clinical Nursing. 2008; 17(15): 2014-2021. PMID:18720572. http://dx.doi.org/10.1111/j.1365-2702.2007.02183.x

[21] Solomon LR. Pain Management in Adults with Sickle Cell Disease in a Medical Center Emergency Department. Journal of the National Medical Association. 2010; 102(11): 1025-32.

[22] Wright K, Adeosun O. Barriers to effective pain management in sickle cell disease. British Journal of Nursing. 2009; 18(3): 158 161. PMID:19223799. http://dx.doi.org/10.12968/bjon.2 009.18 .3 .39043

[23] Booker MJ, Blethyn KL, Wright CJ, et al. Pain management in sickle cell disease. Chronic Illness. 2006; 2(1): 39-50. PMID: 17175681. http://dx.doi.org/10.1177/17423953060020011101

[24] Kohr R, Sawhney M. Advanced practice nurses' role in the treatment of pain. The Canadian Nurse. 2005; 101(3): 30-34.

[25] Matthews E. and Malcolm C. Nurses' knowledge and attitudes in pain management practice. British Journal of Nursing. 2007; 16(3): 174 179. PMID:17363885. http://dx.doi.org/10.12968/bjon.2 007.16 .3 .22972

[26] Lewthwaite BJ, Jabusch KM, Wheeler BJ, et al. Nurses' knowledge and attitudes regarding pain management in hospitalized adults. Journal of Continuing Education in Nursing. 2011; 42: 251-7. PMID:21229930. http://dx.doi.org/10.3928/00220 124-20110103-03

[27] Ferrell B, McCaffery M. Knowledge and Attitudes Survey Regarding Pain. City of Hope. 2009.

[28] Tsai FC, Tsai YF, Chien CC, et al. Emergency nurses' knowledge of perceived barriers in pain management in Taiwan. Journal of Clinical Nursing. 2007; 16: 2088-2095. PMID:17331102. http://dx.doi.org/10.1111/j.1365-2702.2006.01646.x

[29] Al Maran M. Surgical Nurses' Knowledge, Attitude and perceived Barriers to Postoperative Pain Management in Bahrain [Unpublished dissertation]. University of Nottingham.

[30] Wang HL, Tsai YF. Nurses' knowledge and barriers regarding pain management in intensive care units. Journal of Clinical Nursing. 2010; 19: 3188-3196. PMID:20529163. http://dx.doi .org/10. $1111 / \mathrm{j} .1365-2702.2010 .03226 . \mathrm{x}$

[31] Wilson B. Nurses' knowledge of pain. Journal of Clinical Nursing. 2007; 16: 1012-1020. PMID:17518877. http://dx.doi.org/10. $1111 / j .1365-2702.2007 .01692 \cdot x$ 
[32] Abdalrahim M, Majali S, Stomberg M, et al. The effect of postoperative pain management program on improving nurses' knowledge and attitudes toward pain. Nurse Education in Practice. 2011; 11: 250-255. PMID:21186139. http://dx.doi.org/10.1016/j.nepr.2010 .11 .016

[33] Qadire M. Effectiveness of Educational Intervention on Jordanian Nurses' Knowledge and Attitude Regarding Pain Management. British Journal of Medicine and Medical Research. 2014; 4: 14601472. http://dx.doi.org/10.9734/BJMMR/2014/5241

[34] McCaffery M, Robinson ES. Your patient is in pain-here's how you respond. Nursing. 2002; 32: 36-45.

[35] Kaki A, Daghistani M, Msabeh A. Nurses' knowledge of pharmacological measures on acute pain management in Western Saudi Arabia. Saudi Medical Journal. 2009; 30(2): 279-283.
[36] Tse MM, Chan BS. Knowledge and attitudes in pain management: Hong Kong nurses' perspective. Journal of Pain \& Palliative Care Pharmacotherapy. 2004; 18: 47-58. http://dx.doi.org/10.10 80/j354v18n01_04

[37] Erkes E, Parker V, Carr R, et al. An examination of critical care nurses' knowledge and attitudes regarding pain management in hospitalized patients. Pain Management Nursing. 2001; 2 (2): 47-53. PMID:11706770. http://dx.doi.org/10.1053/jpmn. 2001.2 3177

[38] Lai Y, Chen M, Tsai L, et al. Are nurses prepared to manage cancer pain: A national survey of nurses' knowledge about pain control in Taiwan. Journal of Pain and Symptom Management. 2003; 26 (5): 1016-1025. 